\section{Unusual shaped IUS}

I read with interest Anne MacGregor's letter in the January 2013 issue of the Journal describing the removal of an unusually shaped intrauterine system (IUS) and asking if others have had similar experiences. ${ }^{1}$

A couple of years ago I too was alarmed as I removed an IUS through a slightly tight cervical os and noted an odd shape. On closer inspection the device was removed intact, but as in Dr MacGregor's case the hormonal sheath had slipped down the plastic shank thus folding in the arms. In this case, the sheath had actually come much closer to being totally detached.

At the time I was looking through some back journal issues and fortuitously came across a letter in the Faculty Journal written in 2009 by Emma Torbe et al. describing two other similar events. ${ }^{2}$ Since these events occurred years apart it cannot be assumed that this was just one faulty batch of devices, and it would appear that it is something that one needs to be aware does occasionally happen. It highlights the importance of examining the device when it is removed and knowing what the original device was. I have removed quite a few Nova-Ts that have been in situ for too long and have become 'denuded' of copper. The appearance would be very similar to a 'denuded' IUS. The difference is important since no action would be needed in the case of the Nova-T, however further investigation to locate the missing sheath would be necessary in the case of an IUS.

I have kept the misshapen IUS in a specimen bottle as a training aid!

Alwyn R N Lloyd, MBChB, DFSRH

Clinical Assistant in Family Planning, Department of Sexual Health, Princess Alexandra Hospital, Harlow, Essex, UK; alloyd@nhs.net

Competing interests None.

Provenance and peer review Not commissioned; internally peer reviewed.

J Fam Plann Reprod Health Care 2013;39:234. doi:10.1136/jprhc-2013-100641

\section{REFERENCES}

1 MacGregor A. An unusual shaped IUS. J Fam Plann Reprod Health Care 2013;39:64.

2 Torbé EJV, Eddowes H, Aston K. Missing IUS arms? J Fam Plann Reprod Health Care 2009;35:131. 